\title{
Preparation and physicochemical characterization of prazosin conjugated PLGA nanoparticles for drug delivery of flutamide
}

\author{
Ali Fattahi', Mansoureh Ghiasi², Pardis Mohammadi' ${ }^{1}$ Leila Hosseinzadeh ${ }^{3}$, Khosro Adibkia $^{4}$, \\ Ghobad Mohammadi ${ }^{1 *}$
}

${ }^{1}$ Pharmaceutical Sciences Research Center, School of Pharmacy, Kermanshah University of Medical Sciences, Kermanshah, Iran, ${ }^{2}$ Student Research Committee, Kermanshah University of Medical Sciences, Kermanshah, Iran, ${ }^{3}$ Research Center of Oils and Fats, Kermanshah University of Medical Sciences, Kermanshah, Iran, ${ }^{4}$ Drug Applied Research Center, Tabriz University

of Medical Sciences, Tabriz, Iran

\begin{abstract}
In the current work, a sustained drug delivery system of flutamide (FLT) was developed using Poly(D,L-lactide-co-glycolide) (PLGA) decorated bypoly(ethylene glycol) (PEG) grafted prazosin (PLGA-PEG-Praz) as a targeting moiety. In a multi-step reaction, PLGA was linked to PEG and prazosin. The structure of the synthesized polymers was confirmed by FTIR and ${ }^{1} \mathrm{H}-\mathrm{NMR}$. Flutamide-loaded nanoparticles were prepared by quasi-emulsion solvent diffusion technique. The nanoparticles were evaluated for size, zeta potential, polydispersity index, drug crystallinity, loading efficiency, and release properties. Also, the physicochemical properties of the nanoparticles were analyzed using Scanning Electron Microscopy (SEM), Differential Scanning Calorimetry, and Powder X-Ray Diffractometry (XRD). The particle size of nanoparticles was ranged between 191 and $249 \mathrm{~nm}$. Loading efficiency of nanoparticles was about $43 \%-69 \%$. Results showed a steady release rate for nanoparticles compared to that of a pure drug powder. SEM characterization confirmed that particles were in nanosize range. DSC and XRPD results verified a decrease in drug crystallinity in the prepared formulations. In conclusion, the results of this study showed that PLGA-PEG-Praz nanoparticles could be a good choice to improve the physicochemical properties of the drug and these formulations can increase Flutamide efficacy.
\end{abstract}

Keywords: Nanoparticle. PLGA. Flutamide. Prazosin. Prostate cancer. Drug delivery.

\section{INTRODUCTION}

Prostate cancer is one of the most common cancers in adult males in the United State (Alldredge et al., 2013; Anitha et al., 2013). Treatment of advanced prostate cancer relies mainly on non-specific therapies such as chemotherapy and ionizing radiation, which have a low efficacy and are highly toxic to normal tissues (Xu et al., 2013).

The function and proliferation of prostate cells are physiologically dependent on androgens (Heidenreich et al., 2009). Flutamide (FLT) is a potent non-steroidal anti-androgen drug clinically used for the treatment of advanced prostate cancer (Anitha et al., 2013; Samy

\footnotetext{
*Correspondence: G. Mohammadi. Pharmaceutical Sciences ResearchCenter, School of Pharmacy, Kermanshah University of Medical Sciences, Kermanshah, Iran. Tel: +98 8334276482 / Fax: +98 8334276482. E-mail: ghobadmohammadi@yahoo.com
}

2012). This drug reduces testosterone only on frequent administration because it undergoes extensive first-pass metabolism, and its metabolites are less active (Anitha et al., 2013; Samy, 2012). In addition, the therapeutic effect of the FLT is hampered by a low bioavailability due to its low water solubility $(9.45 \mathrm{mg} / \mathrm{L})$ and poor wettability (Anitha et al., 2013; Samy, 2012; Zuo et al., 2000). Moreover, high doses of FLT cause hepatotoxicity (Adlin, Gowthamarajan, Somashekhara, 2009).

Application of polymer-based nanoparticles (NPs) using biodegradable polymers for drug delivery is widely expected to change the landscape of the pharmaceutical and biotechnology industries in the near future (Farokhzad, Langer 2009; van Vlerken, Vyas, Amiji, 2007). Polymeric NPs have been shown to improve drug efficacy through sustained delivery over a long time period or drug delivery with a minimization of side effects (Singh, Lillard, 2009).

Poly(D,L-lactide-co-glycolide) (PLGA) belongs to the best-known class of biodegradable polymers 
for sustained and controlled release. This polymer is a biodegradable and biocompatible and is hydrolytically degraded into the non-toxic monomers, lactic acid, and glycolic acid. PLGA polymers are already approved by the US Food and Drug Administration (FDA). Besides, several micro/nanoformulations of PLGA have been adapted to various types of drugs; e.g., hydrophilic and hydrophobic molecules, small molecules, and macromolecules (Valizadeh et al., 2012; Danhier et al., 2012).

Malignant tumors can be treated with the PLGA NPs through passive targeting. Passive targeting takes advantage of nanoparticles' size and exploits the unique anatomical and pathological abnormalities of the tumor vasculature; i.e., enhanced permeability and retention (EPR) effect. While NPs can passively target tumors through the EPR effect, the main challenge of using the NPs for drug delivery to tumors is their clearance by the mononuclear phagocytic system from the bloodstream (van Vlerken et al., 2007; Mohanraj, Chen, 2006). The recognition of NPs by reticuloendothelial system (RES) cells can be limited by imparting stealth shielding on the NP surface. Poly(ethylene glycol)(PEG) modification known as PEGylation has emerged as a common strategy to ensure such stealth-shielding and long circulation of the NPs (Jokerst et al., 2011). PEG is a coiled polymer of repeating ethylene ether units that provides hydrophilic and neutral chains at the particle surface and repel plasma proteins (van Vlerken et al., 2007; Mohanraj, Chen, 2006). PEG coatings facilitate a stealth-NP formulation, which allows escaping from RES cells and, therefore, increases the NP's systemic circulation time (van Vlerken et al., 2007; Liu et al., 2010).

In general, limitations of conventional treatments are associated with the non-specific targeting of the therapeutic modalities (Wadajkar et al., 2013). Active targeting can be realized by "decorating" the NP surface with specific ligands (Zhang, Lee, Feng, 2007). Extensive studies have been performed to achieve the active targeting of NPs in order to deliver drugs to the target cells, based on ligand-receptor or antigen-antibody interactions (Mohanraj, Chen, 2006; Pan, Feng, 2009). The receptorligand complex can be progressed to internalization via endocytosis, which may promote the cytosolic delivery of drugs. Targeted NPs demonstrated considerable advantages versus non-targeted NPs in achieving lower levels of side effects and a higher therapeutic efficiency (Ebrahimnejad et al., 2011; Pan, Feng, 2008; Zhao, Yung, 2008).

Prazosin is an $\alpha_{1}$-adrenoceptor antagonist used as a first-line medical treatment of prostatic hyperplasia related to lower urinary tract symptoms. It binds to $\alpha_{1}$ - adrenoceptors on smooth muscle cells of the prostate and bladder tissues and consequently reduces muscle tone and relieves bladder obstruction. Furthermore, several lines of evidence suggest that prazosin induces apoptosis in prostate cancer and inhibits angiogenesis (Lin et al., 2007; Liao et al., 2011). Therefore, decoration of prostatic anticancer drug-loaded NPs by prazosin not only provides receptor-mediated endocytosis and active targeting but also improves system efficacy through its synergic anticancer effects.

This study was conducted to describe the preparation of FLT-loaded PLGA and PLGA-PEG-prazosin (PLGAPEG-Praz) NPs to sustain the release of FLT and improve the physicochemical properties of the drug. Moreover, the relative cytotoxic potencies of FLT and FLT-loaded PLGA-PEG-Praz are evaluated in PC-3 prostate cancer cell line.

\section{MATERIAL AND METHODS}

\section{Material}

Poly(D,L-lactide-co-glycolide) (PLGA) (50:50 D,L-lactide:glycolide) with terminal carboxylate groups and average molecular weight of 44,000 g/mol(Resomer RG 502) was obtained from Purac, The Nederland. Diethyl ether, dichloromethane (DCM), polyvinyl alcohol (PVA, $\left.\mathrm{M}_{\mathrm{w}} 88,000\right)$ and poly(ethylen glycol) (PEG, $\left.\mathrm{M}_{\mathrm{w}} 6,000\right)$ were purchased from Merck,Germany.Dimethylaminopyridine (DMAP), dimethyl sulfoxide (DMSO), FLT, prazosin, dimethylaminopropylcarbodiimide (EDC) and $N$-hydroxysuccinimide (NHS) were all purchased from Sigma-Aldrich, USA. $N, N$ '-diisopropylcarbodiimide (DIPC) was obtained from Fluka, Japan. PEG was dried azeotropically with toluene, and dichloromethane was dried over $\mathrm{CaH}_{2}$ and stored over molecular sieve (4 $\AA$ ). Other compounds were used without any purification.

\section{Methods}

\section{Synthesis of the PLGA-PEG-Praz conjugate}

The synthesis of Prazosinconjugates followed a three-step reaction (Figure 1): synthesis of PEG$\mathrm{COOH}$, conjugation of prazosin to PEG (Praz-PEG) and conjugation ofPLGA with Praz-PEG to form PLGA-PEGPraz. (Figure 1)

\section{- Synthesis of PEG-COOH}

PEG-COOH was prepared according to the method developed by SijianHou et al (2007) (Hou, McCauley and Ma 2007), with minor modifications. Briefly, dried 


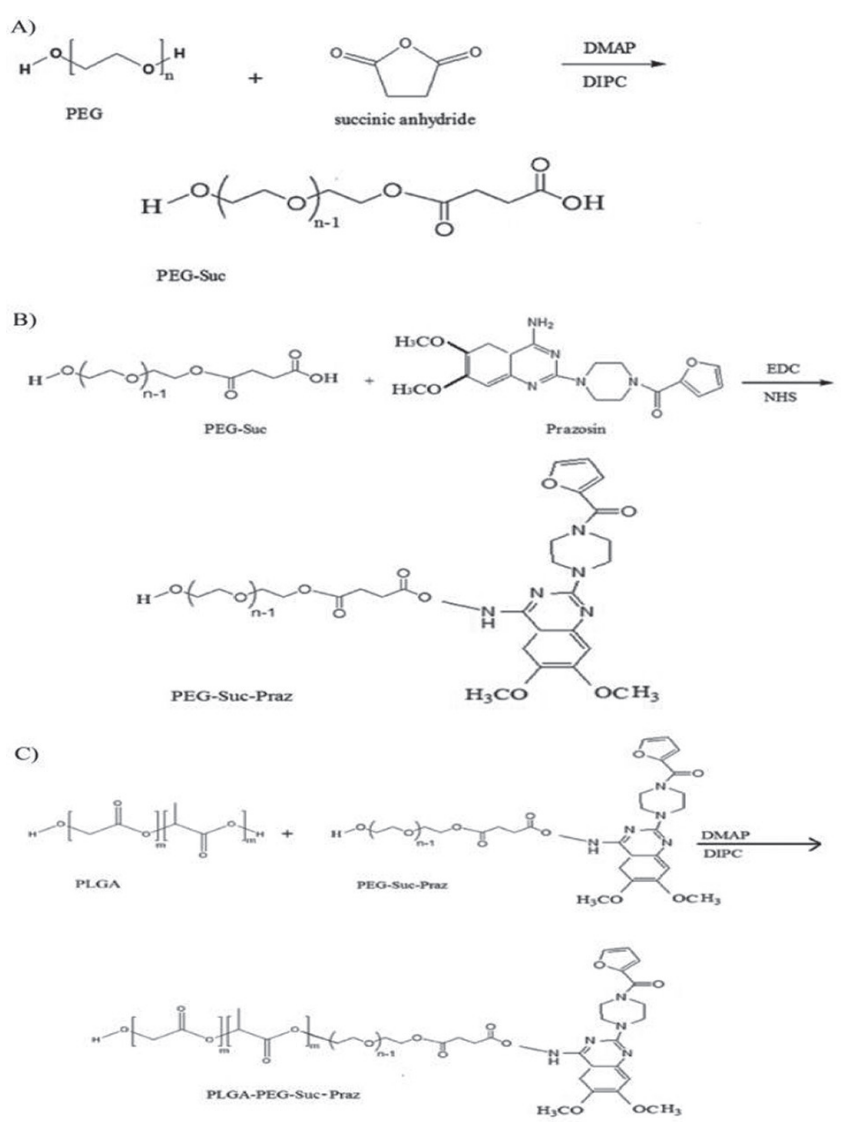

FIGURE 1 - Chemical conjugation of PLGA with PEG-Praz.

PEG, succinic anhydride, $N, N$ '-diisopropylcarbodiimide (DIPC), and 4-dimethylaminopyridine (DMAP) at molar ratios of 1,1.4,1.4 and 1.2 were used respectively. Succinic anhydride andDMAP were completely dissolved in $15 \mathrm{~mL}$ of anhydrous DCM and kept at $0{ }^{\circ} \mathrm{C}$ for $30 \mathrm{~min}$. PEG and DIPC were mixed in $15 \mathrm{~mL}$ of DCM and transferred slowly into the succinic anhydride solution using a syringe underthe nitrogen atmosphere. The solution was stirred at $0{ }^{\circ} \mathrm{C}$ for $2 \mathrm{~h}$ and the reaction was continued in DCMunder nitrogen gas at room temperature for $48 \mathrm{~h}$. At the end of reaction time, the insoluble solid was filtered off. The PEG-COOH was precipitated in cold diethyl ether. The precipitates were again dissolved in DCM and re-precipitated in cold diethyl ether. The precipitates were washed by diethyl ether for several times and dried under vacuum at room temperature overnight.

PEG-COOH: ${ }^{1} \mathrm{H}$ NMR (DMSO, $\left.400 \mathrm{MHz}\right) \delta(\mathrm{ppm})$ : 2.42-2.45 (4H, d), 3.51 (4H, a), 3.58-3.6 (2H, b), 4.1-4.

\section{- Synthesis of Praz-PEG}

The amide reaction was carried out using the similar methods reported previously (Hou, McCauley, $\mathrm{Ma}, 2007)$, with minor modifications.PEG-COOH was reacted with EDC and $N$-hydroxysuccinimide (NHS) in anhydrous DMSO at stoichiometric molar ratio of 1,2 and 2 , respectively for $6 \mathrm{~h}$ at room temperature. Then the excess amount of prazosin dissolved in DMSO and transferredslowly into the activated PEG solution using a syringe under the nitrogen atmosphere. The reaction was continued under nitrogen gas protection and stirred at room temperaturefor $72 \mathrm{~h}$.

Final solution was added to a dialysis membrane tube ( $\mathrm{M}_{\mathrm{w}}$ cut-off: 3500 , orange). The membrane was sealed and suspended in $2 \mathrm{~L}$ of deionized water and the solution was stirred gentlyat room temperature.After 2 $\mathrm{h}$ the deionized water was replaced by a fresh batch of deionized water and the process was repeated four times. The resultant product was obtained by freeze-drying.

Praz-PEG: ${ }^{1} \mathrm{H}$ NMR (DMSO, $\left.400 \mathrm{MHz}\right) \delta(\mathrm{ppm})$ : 2.42-2.46 (4H, d), 3.58-3.6 (2H, b), 3.51 (4H, a), 3.79,3.84 $\left(6 \mathrm{H}, \mathrm{OCH}_{3}\right), 4.11-4.12(2 \mathrm{H}, \mathrm{c}), 6.64-6.66\left(1 \mathrm{H}, \mathrm{H}_{4}\right.$-Furan $)$, 6.75 (1H, $\mathrm{H}_{5}$-Quinazoline), 7.03-7.04 (1 $\mathrm{H}, \mathrm{H}_{5}$-Furan), $7.0435\left(1 \mathrm{H}, \mathrm{H}_{8}\right.$-Quinazoline), 7.87-7.86 (1H, $\mathrm{H}_{3}$-Furan).IR $\left(\mathrm{KBr}, \mathrm{cm}^{-1}\right): 3448(\mathrm{O}-\mathrm{H}, \mathrm{N}-\mathrm{H}$ stretch), 2885 (C-H, stretch), $1735(\mathrm{C}=\mathrm{O}$, stretch, ester $), 1635(\mathrm{C}=\mathrm{O}$, stretch, amide $)$, 1597 (C=C, stretch), 1107 (C-O-C, stretch), 1060 (C-O, stretch, alcohol).

\section{- Synthesis of PLGA-PEG-Praz}

PLGA-PEG-Praz was synthesized by reacting PEG-Praz,PLGA, N,N'-diisopropylcarbodiimide (DIPC), and 4-dimethylaminopyridine (DMAP) at molar ratio of 2,1,2, and 2respectively. PLGA was dissolved in $30 \mathrm{~mL}$ of anhydrous DCM, and DIPC,DMAP and PEGPrazwereaddedto this solution at $0{ }^{\circ} \mathrm{C}$.

The solution was stirred at $0{ }^{\circ} \mathrm{C}$ for $2 \mathrm{~h}$, and then the ice bath was taken out to warm solution to room temperature.

The reaction was continued in dichloromethane under nitrogen gas at room temperaturefor $48 \mathrm{~h}$. At the end of reaction time, the insoluble solid was filtered off. The PLGA-PEG-Praz was precipitated in cold diethyl ether. The precipitates were dissolved in DCM and re-precipitatedin cold diethyl ether. The precipitates were washed by diethyl ether and deionized water for several times and dried under vacuum at room temperature overnight.

PLGA-PEG-Praz: ${ }^{1} \mathrm{H}$ NMR (DMSO, $\left.400 \mathrm{MHz}\right) \delta$ (ppm): 3.58-3.6 (2H, b), $3.51(4 \mathrm{H}, \mathrm{a}), 4.1-4.13(2 \mathrm{H}, \mathrm{c}), 3.86$ $\left(\mathrm{OCH}_{3}\right), 1.47-1.48\left(3 \mathrm{H},\left(\left(\mathrm{OCH}\left(\mathrm{CH}_{3}\right) \mathrm{C}(\mathrm{O}) \mathrm{CH}_{2} \mathrm{C}(\mathrm{O})\right)_{\mathrm{n}}\right)\right.$, $4.92\left(2 \mathrm{H},\left(\left(\mathrm{OCH}\left(\mathrm{CH}_{3}\right) \mathrm{C}(\mathrm{O}) \mathrm{C}_{2} \mathrm{C}(\mathrm{O})\right)_{\mathrm{n}}\right), 5.18-5.27(1 \mathrm{H}\right.$, $\left(\left(\mathrm{OC} \underline{\mathrm{H}}\left(\mathrm{CH}_{3}\right) \mathrm{C}(\mathrm{O}) \mathrm{CH}_{2} \mathrm{C}(\mathrm{O})\right)_{\mathrm{n}}\right) \cdot \mathrm{IR}\left(\mathrm{KBr}, \mathrm{cm}^{-1}\right): 3245-3510$ (O-H,N-H, stretch), 2854-2993 (C-H, stretch), 1751 (C=O, stretch, ester $), 1654(\mathrm{C}=\mathrm{O}$, stretch, ester $), 1631(\mathrm{C}=\mathrm{O}$, stretch, amide), $1543(\mathrm{C}=\mathrm{C}$, stretch $), 1107$ (C-O-C, stretch), 1060 (C-O, stretch, alcohol). 


\section{Preparation of nanoparticles}

NPs with $1: 2,1: 3$ and $1: 5$ ratios of the drug to PLGA and $1: 3$ ratio of the drug to targeted PLGA were prepared by nano-precipitation according to the modified quasi emulsion solvent diffusion technique (Lee, Na, Bae, 2003).

FLT with PLGA or PLGA-PEG-Praz powder were co-dissolved in internal phase (2.5 $\mathrm{mL}$ DMSO) at room temperature $\left(25^{\circ} \mathrm{C}\right)$. Typically, different ratios of drug and polymer, with the total amount of $100 \mathrm{mg}$, were codissolved in DMSO. The resulting organic solution was injected at the constant rate of $0.5 \mathrm{~mL} / \mathrm{min}$ in aqueous phase $(40 \mathrm{~mL})$ containing PVA $(1 \% \mathrm{w} / \mathrm{v})$, as a stabilizing agent.

The process was carried out under homogenization for 5 min using the T18 basic homogenizer (IKA, Brasil). The agitation speed was $12000 \mathrm{rpm}$ in an ice-water bath. DMSO was eliminated at the room temperature under stirring for $12 \mathrm{~h}$. The final nano-suspension was centrifuged (Avanti TM J-25, Beckman, USA) at $14000 \mathrm{rpm}$ for $20 \mathrm{~min}$ and the precipitated NPs were washed twice with water, using the previously described centrifugation approach. Then NPs were freeze-dried.

\section{Structural characterization of polymeric conjugates}

Infrared (IR) and ${ }^{1} \mathrm{H}$ NMR spectra were prepared in order to confirm the chemical structure of polymers. Infrared spectra were obtained using a ShimadzoIrprestige-21spectrometer. The samples were pressed into $\mathrm{KBr}$ pellets for analysis. ${ }^{1} \mathrm{H}$ NMR measurements of samples in DMSO were performed on a $400-\mathrm{MHz}$ proton NMR spectrometer (AC-400, BrukerBiospin, Germany), Chemical shifts were expressed asparts per million, ppm.

\section{Evaluation of the particle size, zeta potential and morphology of nanoparticles}

The particle size and size distribution of the prepared NPs were determined via the laser diffraction particle size analyzer (Zetasizer, Malvern, UK). To assess the size of NPs, the dried powder samples were suspended in distilled water and slightly sonicated (Tecna3, Tecno-Gaz, Italy) at $70 \%$ amplitude for $30 \mathrm{sec}$ before measurement. The mean diameter and size distribution of the resulted homogeneous suspension were assessed, subsequently.

The particle surface charge was quantified as zeta potential $(\zeta$ potential) using a Zetasizer. Measurements were performed in distilled water.

The morphology of the NPs was investigated by scanning electronmicroscopy (SEM, LEO440i, LeoElectronMicroscopyLtd., Cambridge, UK) at an accelerating voltage of $20 \mathrm{kV}$. Prior to examination, samples were prepared on aluminum stubs and coated with gold under argon atmosphere by a sputter coater.

\section{Differential scanning calorimetry (DSC)}

Accurately weighed samples, equivalent to $3 \mathrm{mg}$ of FLT, were placed into the sealed standard aluminum pans with lids. Afterward, the physical status of the FLT inside the NPs was ascertained using the differential scanning calorimetry thermogram analysis, (DSC60, Shimadzu, Japan).

Thermal behavior of the samples was investigated at a scanning rate of $40{ }^{\circ} \mathrm{C} / \mathrm{min}$ covering temperature range of $20-240^{\circ} \mathrm{C}$.

The aluminum oxide and indium powders were employed as referenceand standard, respectively. DSC analysis of pure FLT, PLGA and PLGA-PEG-Praz was performed to identify the drug melting point peakand polymer glass transition temperature $\left(\mathrm{T}_{\mathrm{g}}\right)$.

\section{$X$-ray powder diffraction}

The X-ray powder diffraction (PXRD), pattern of the drug, PLGA, PLGA-PEG-Praz, NPs and physical mixture in the 1:3 drug to polymer ratio were recorded using an automated X-ray diffractometer (Siemens850 ,Germany). Cross-section of the samples were taken and held in place on a quartz plate for exposure to $\mathrm{Cu} \mathrm{K \alpha}$ radiation of wavelength $1.5406 \AA$. Diffractograms were run at scanning rate of $0.06^{\circ} \mathrm{cm}^{-1}$, over the range of 5-60 and with sampling intervals of 0.02 .

\section{Encapsulation efficiency}

FLT content in the NPs was determined by UV-V is spectrophotometry (Mohammadi et al., 2011). Three samples from each preparation, equivalent to $6 \mathrm{mg}$ drug were chosen randomLy and were dissolved in DMSO. After appropriate dilution, the absorbance was measured using UV spectrophotometer at $315 \mathrm{~nm}$ using DMSO containing polymer as a blank.

Encapsulation efficiency was calculated by the following equation:

$$
\mathrm{EE}=\frac{W}{W 0} \times 100
$$

where $\mathrm{W}$ is the weight of drug entrapped in NPs and Wo is the weight of the initial feeding drug.

\section{Invitro drug release}

The in vitro drug release study was carried out using dialysis method in sink conditions (Elgindy et al., 2011). A known weight of NPs (equivalent to $5 \mathrm{mg}$ drug) was placed in a cellulosic membrane tube $\left(\mathrm{M}_{\mathrm{w}}\right.$ cutoff of 3500) and was added to $75.75 \mathrm{~mL}$ PBS ( $\mathrm{pH} 7.4)$ containing $0.2 \%(\mathrm{w} / \mathrm{v})$ tween 80 . The container transferred into the shaker incubator at $37^{\circ} \mathrm{C}$ with continuous orbital mixing $(100 \mathrm{rpm})$. At 
specified times intervals $(0.5,1,2,3,4,6,8,10,12,24,26$, and $28 \mathrm{~h}), 0.4 \mathrm{~mL}$ samples were removed and filtered through a $0.45 \mu$ msiringfilter. After each sampling, an equal volume of pre-warmed fresh dissolution media was replaced. The drug concentrations in the samples were analyzed at $315 \mathrm{~nm}$ using a spectrophotometer (Shimadzu, Japan). The cumulative amount of the released FLT was calculated considering the replaced volume of the dissolution medium and the cumulative percentage of the released FLT was plotted versus time. The mean calculated values were obtained from Three replicates.

\section{MTT cell proliferation assay}

PC-3 (human prostate cell carcinoma) was obtained from Pasteur Institute (Tehran, Iran). The cells were cultured in Dulbecco's modified Eagle's medium (DMEM-F12) with $10 \%(\mathrm{v} / \mathrm{v})$ fetal bovine serum, $100 \mathrm{UmL}-1$ penicillin, and $100 \mathrm{mgmL}-1$ streptomycin. Cell proliferation was determined using the 3-[4,5-dimethylthiazol-2-yl)-2,5diphenyltetrazoliumbromide] (MTT) assay. Briefly, the cells were plated in 96-well cell culture plates at a cell density of $15 \times 10^{4}$ cells per well. After $48 \mathrm{~h}$ the medium was replaced with fresh medium containing increasing concentrations of the FLT and FLT and FLT -loaded PLGA-PEG-Praz. A negative control of untreated cells was also included. The cells were incubated for a further $48 \mathrm{~h}$, after which a $0.5 \mathrm{mg} / \mathrm{mL}$ MTT solution ( $10 \mu \mathrm{L}$ per well) was added and the cells incubated for an additional $4 \mathrm{~h}$. Then, the medium was removed, and the purple formazan crystals were dissolved in DMSO (200 $\mu \mathrm{L} /$ well). Absorbance was determined on an ELISA plate reader (Biotek, H1 M) with a test wave length of $570 \mathrm{~nm}$ and a reference wavelength of $630 \mathrm{~nm}$ to obtain sample signal (OD570-OD630).

\section{RESULTS AND DISCUSSION}

\section{Characterization of the synthesized polymers}

The structure of the synthesized polymers was confirmed by FTIR and ${ }^{1}$ HNMR. FTIR spectra of the Prazosin, PLGA, PEG-Succ, PEG-Praz, and PLGA-PEGPraz are shown in Figure 2. As can be observed from the PEG-Succinic acid spectrum, peaks at 2,884 and 2,993 $\mathrm{cm}^{-1}$ correspond to $\mathrm{C}-\mathrm{H}$ stretching. The absorption band at $1,107 \mathrm{~cm}^{-1}$ is indexed to the characteristic C-O-C stretching vibrations of the repeated $\mathrm{OCH}_{2} \mathrm{CH}_{2}$ units of PEG. The appearance of the absorption band at $1,735 \mathrm{~cm}^{-1}$ is indexed to the $\mathrm{C}=\mathrm{O}$ stretching vibrations of the carbonyl-ester, which indicates the successful synthesis of PEG-Succinic acid. In the PEG-Prazspectrum, the absorption bands at 1,635 and $671.23 \mathrm{~cm}^{-1}$ are indexed to the amide $\mathrm{C}=\mathrm{O}$ stretching of
Prazosin. The absorption band at $1,597 \mathrm{~cm}^{-1}$ is related to the $\mathrm{C}=\mathrm{C}$ stretching of the aromatic ring in prazosin.

Finally, the PLGA-PEG-Praz spectrum shows an absorption band at $1,107 \mathrm{~cm}^{-1}$ is indexed to the characteristic $\mathrm{C}-\mathrm{O}-\mathrm{C}$ stretching vibrations of the repeated $\mathrm{OCH}_{2} \mathrm{CH}_{2}$ units of PEG. The absorption band at $1,735 \mathrm{~cm}^{-1}$ is indexed to the $\mathrm{C}=\mathrm{O}$ stretching vibrations of the carbonyl ester and the absorption bands at $1,635 \mathrm{~cm}^{-1}$ are indexed to amide $\mathrm{C}=\mathrm{O}$ stretching. A sharp peak indexed to the $\mathrm{C}=\mathrm{O}$ stretching vibrations of the ester carbonyl group in PLGA appeared at $1,751 \mathrm{~cm}^{-1}$.

${ }^{1} \mathrm{H}-\mathrm{NMR}$ spectra are shown in Figure 3 to further confirm the formation of the synthesized polymers. The sharp single peak at $3.51 \mathrm{ppm}$ in PEG spectrum is indexed to the methylene protons of PEG unit home sequences. The chemical shifts at $\delta=2.42-2.46 \mathrm{ppm}$ are indexed to succinate moieties of PEG-Succ (Figure 3C). The peaks at $3.79,3.84$, and $3.86 \mathrm{ppm}$ are indexed to the protons on $\mathrm{OCH}_{3}$ groups, and the chemical shifts at 6.64-6.66, 6.75, 7.03, 7.04, 7.86, and $7.87 \mathrm{ppm}$ (Figure 3E) are ascribed to other protons in Prazosin, which confirm a successful conjugation (Zhao et al., 2010).

Hydrogen atoms in the methylene group of the lactic acid unit of the PLGA copolymer resonated at 5.18-5.27 ppm, whereas those of the methylene group of the glycolic acid unit appeared at $4.92 \mathrm{ppm}$. Here, the $\mathrm{CH}$ peak at approximately $1.48 \mathrm{ppm}$ confirms the presence of PLGA (Figure 3E) (Mahalwar et al., 2012).

\section{Loading study}

Loading results revealed a maximum FLT loading of about $69.1 \%$ that increased linearly with the increase in PLGA amount. This observation may be attributed to the higher viscosity of the internal organic phase at higher PLGA ratios, which in turn would decrease the diffusion coefficient of the drug. Furthermore, at higher polymer ratios, the extent of drug loss during the washing procedure was reduced (Koopaei et al., 2012). Compared to PLGA NPs, PLGA-PEG-PrazNPs had a higher loading efficiency, which could be related to a higher viscosity (Cun et al., 2010) and to the NPs' hydrophilic shells, which increase the affinity of FLT to its hydrophobic core and consequently increases the loading efficiency.

\section{Physicochemical characterizations}

\section{Characterization of nanoparticles: size, morphology, and zeta potential}

Submicron particles ranging from $191.8 \pm 23.4$ to $249.13 \pm 33.6 \mathrm{~nm}$ with a narrow size range and a relatively 

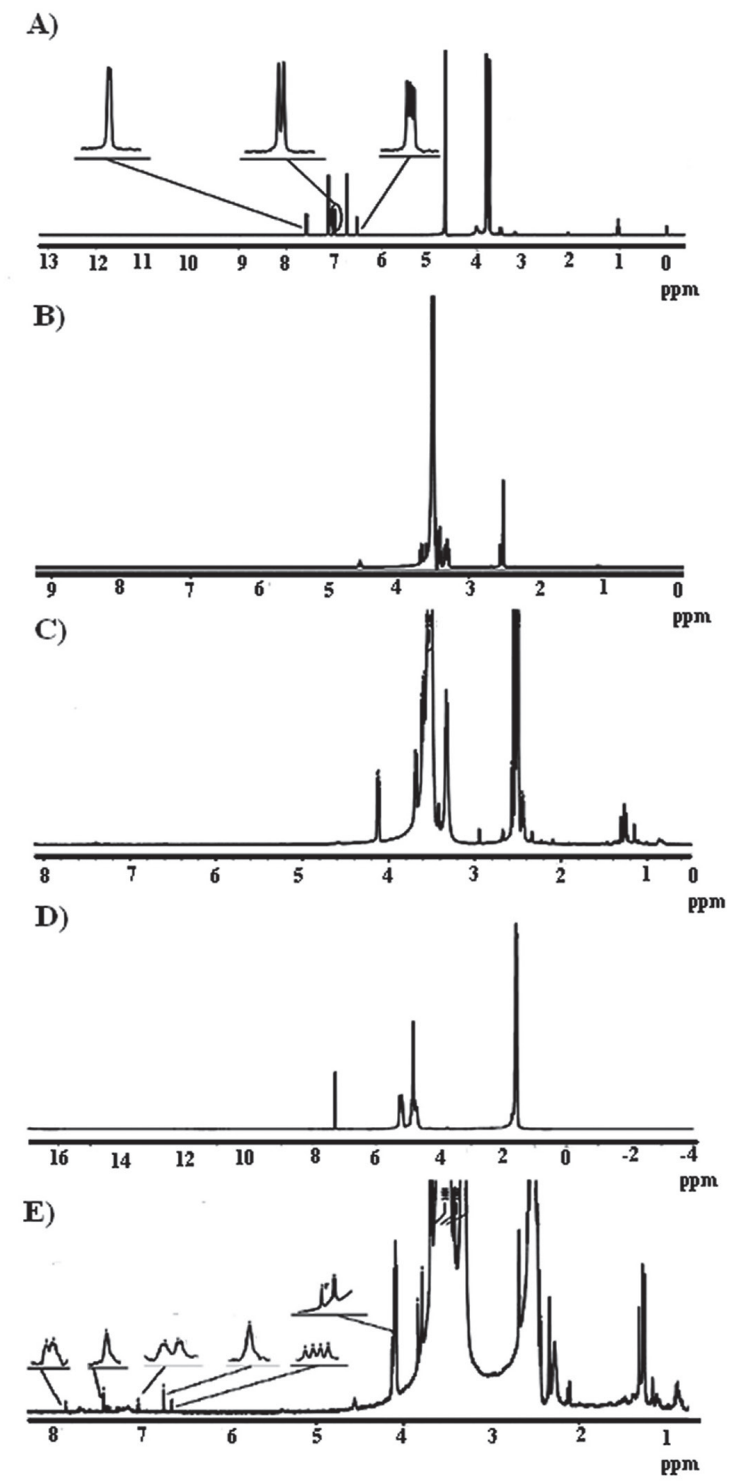

FIGURE 2 - FT-IR of the prazosin (A), PLGA (B), PEG (C), PEG-succinic acid (D), PEG-Praz(E), and PLGA-PEG-Praz (F).

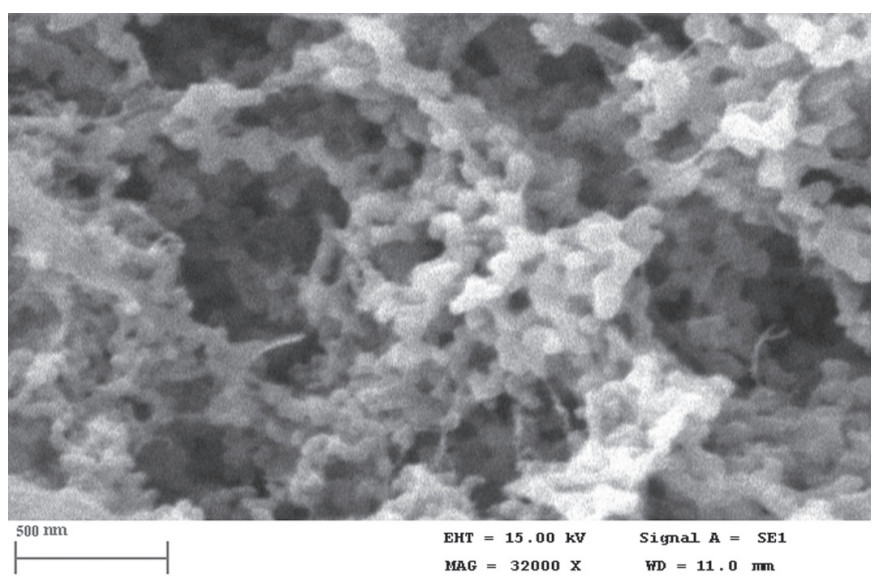

FIGURE 3 - ${ }^{1} \mathrm{HNMR}$ of the prazosin (A), PEG (B), PEG-succinic acid (C), PLGA (D), PEG-Praz (E). monodisperse distribution were achieved using a modified quasi-emulsion solvent diffusion technique (Table I).

The zeta potentials of NPs are shown in Table I. Given the neutral charge of FLT, despite an increase in the PLGA in NPs, the surface charge remained constant. Zeta potential gives an idea about the charge of the particle; the higher the zeta potential, the higher the charge on the particle surface would be. The surface charge on the particles could control the particles stability of the nanoparticulate formulation through strong electrostatic repulsion of particles with each other. The nanoparticles demonstrated negative zeta potential values $(-1.98 \mathrm{mV}$ to $-1.66 \mathrm{mV}$ ), which can be attributed to the presence of the ionized carboxyl group of PLGA on the particles' surface. Interestingly, pure PLGA showed a much lower zeta potential $(-30 \mathrm{mV}$ to $-50 \mathrm{mV})$, suggesting that drug adsorbs on the surface of the nanoparticles. Also, the values of the zeta potential of drug PLGA-PEG-Praz were obviously affected by the presence of PEG chains.

SEM experiments revealed a spherical morphology and a relatively smooth surface for the resultant NPs (Figure 4, Table I).

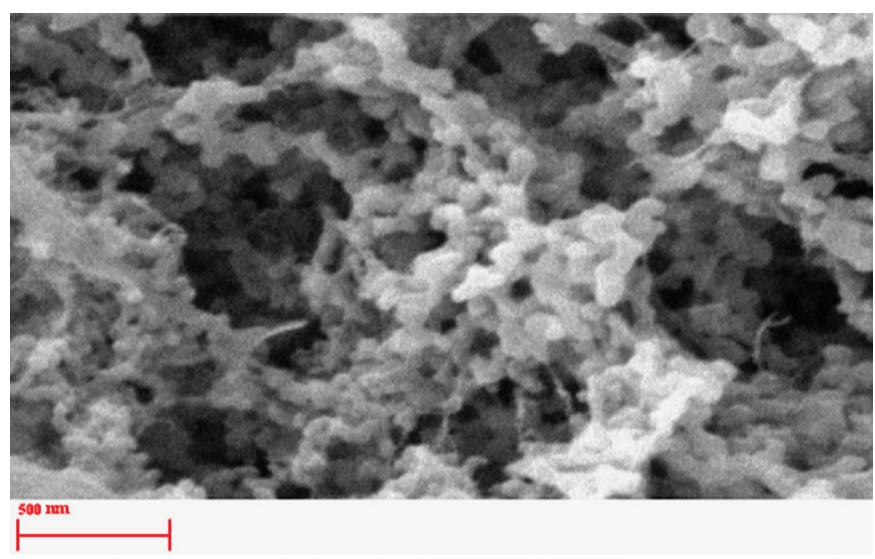

FIGURE 4 - SEM image of flutamide nanoarticles.

\section{PowderX-ray diffraction (PXRD) and differential scanning calorimetry (DSC)}

PXRD and DSC experiments were carried out to assess the crystallinity properties and scrutinize any possible interactions between the drug and polymer in the prepared NPs.

DSC thermograms of intact FLT, PLGA, physical mixtures (1:3 ratio), and NPs are shown in Figure 5. DSC is one of the most common methods to assess the physicochemical interactions between drugs and polymers in a given formulation. Intact FLT powder showed an endothermic peak corresponding to its melting point at $119.92^{\circ} \mathrm{C}$ (Figure 5). There was a sharp drop in the FLT 
Preparation and physicochemical characterization of prazosin conjugated PLGA nanoparticles for drug delivery of Flutamide

TABLE I - Polydispersity $( \pm \mathrm{SD})$, mean $( \pm \mathrm{SD})$ particle diameter, zeta potential, and encapsulation efficiency $( \pm \mathrm{SD})$ of the various nanoparticles

\begin{tabular}{ccccc}
\hline Formulations & Polydispersity & $\begin{array}{c}\text { Mean particle size } \\
(\mathbf{n m})\end{array}$ & $\begin{array}{c}\text { Zeta potential } \\
(\mathbf{M v})\end{array}$ & $\begin{array}{c}\text { Encapsulation } \\
\text { efficiency }(\mathbf{\%})\end{array}$ \\
\hline 1:3Drug: PLGA-PEG-Praz & $0.260 \pm 0.030$ & $194.60 \pm 37.0$ & -1.82 & $69.1 \% \pm 4.7$ \\
1:2Drug:PLGA & $0.180 \pm 0.014$ & $191.80 \pm 23.4$ & -1.80 & $43.0 \% \pm 4.0$ \\
1:3Drug:PLGA & $0.200 \pm 0.012$ & $219.70 \pm 6.2$ & -1.66 & $50.0 \% \pm 5.0$ \\
1:5 Drug:PLGA & $0.162 \pm 0.050$ & $249.13 \pm 33.6$ & -1.98 & $64.0 \% \pm 4.5$ \\
\hline
\end{tabular}

melting point and enthalpy of fusion in the PLGA NP thermograms at 1:2,1:3, and 1:5 drug to polymer ratios (Figure 5A) and PLGA-PEG-Praz NPs at a 1:3 ratio (Figure 5B), suggesting that the formulation process induced an amorphous phase in the samples. The glasstransition temperature of PLGA was found to be $56.01^{\circ} \mathrm{C}$.
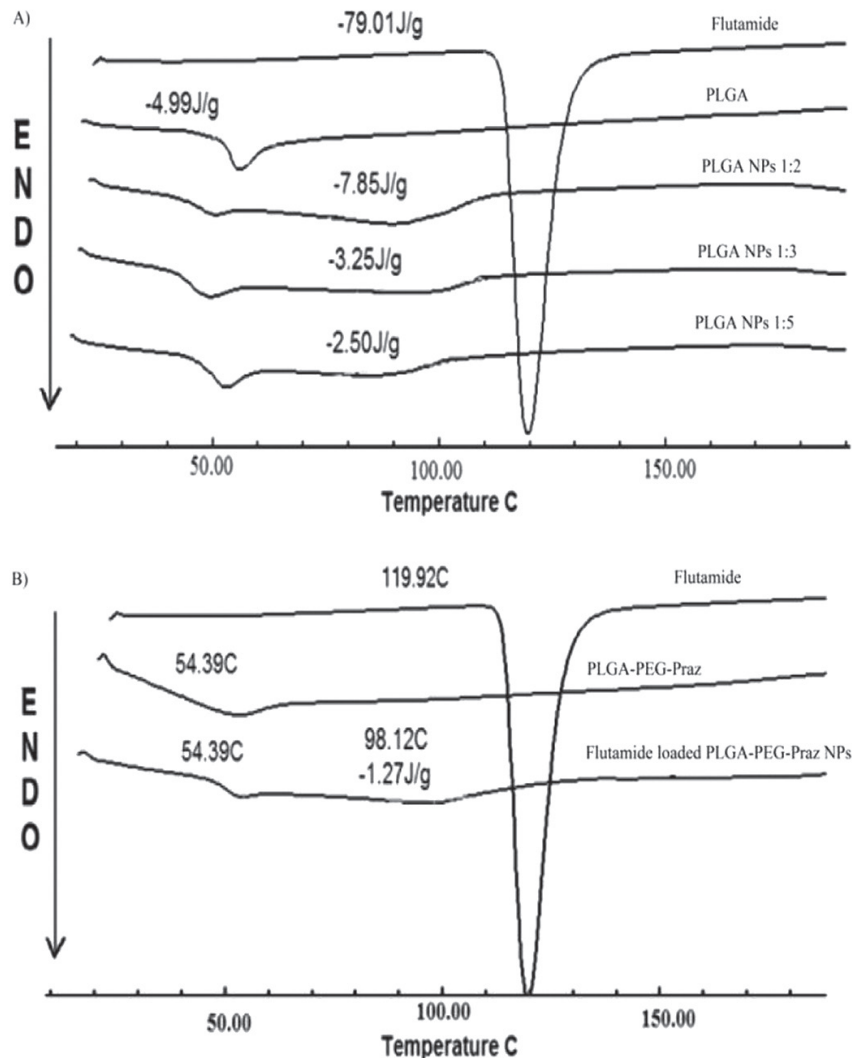

FIGURE 5 - DSC curve of the intact flutamide powder, PLGA, PLGA-PEG-Parz, physical mixture of drug: PLGA 1:3, nanoparticles of drug: PLGA 1:3, and PLGA-PEG-Parz nanoparticles.

XRD is frequently used to analyze the degree of sample crystallinity. As shown by the XRD patterns (Figure 6), intact FLT had distinct peaks at $2 \theta \mathrm{s}$ of $8^{\circ}, 12^{\circ}$, $17^{\circ}, 19^{\circ}, 3.8^{\circ}, 24^{\circ}, 28.5^{\circ}$, and $32^{\circ}$, corresponding to the crystal form of FLT. This observation was confirmed by the DSC melting endotherm at $119.92^{\circ} \mathrm{C}$. There was no clear peak in the XRD pattern for the amorphous polymer. The XRD pattern of the physical mixtures indicated that the intensities of typical peaks for the intact drug were lowered due to a dilution effect without a qualitative disparity in drug diffractogram. NPs were characterized by the absence of distinct (or unclear) diffraction peaks,

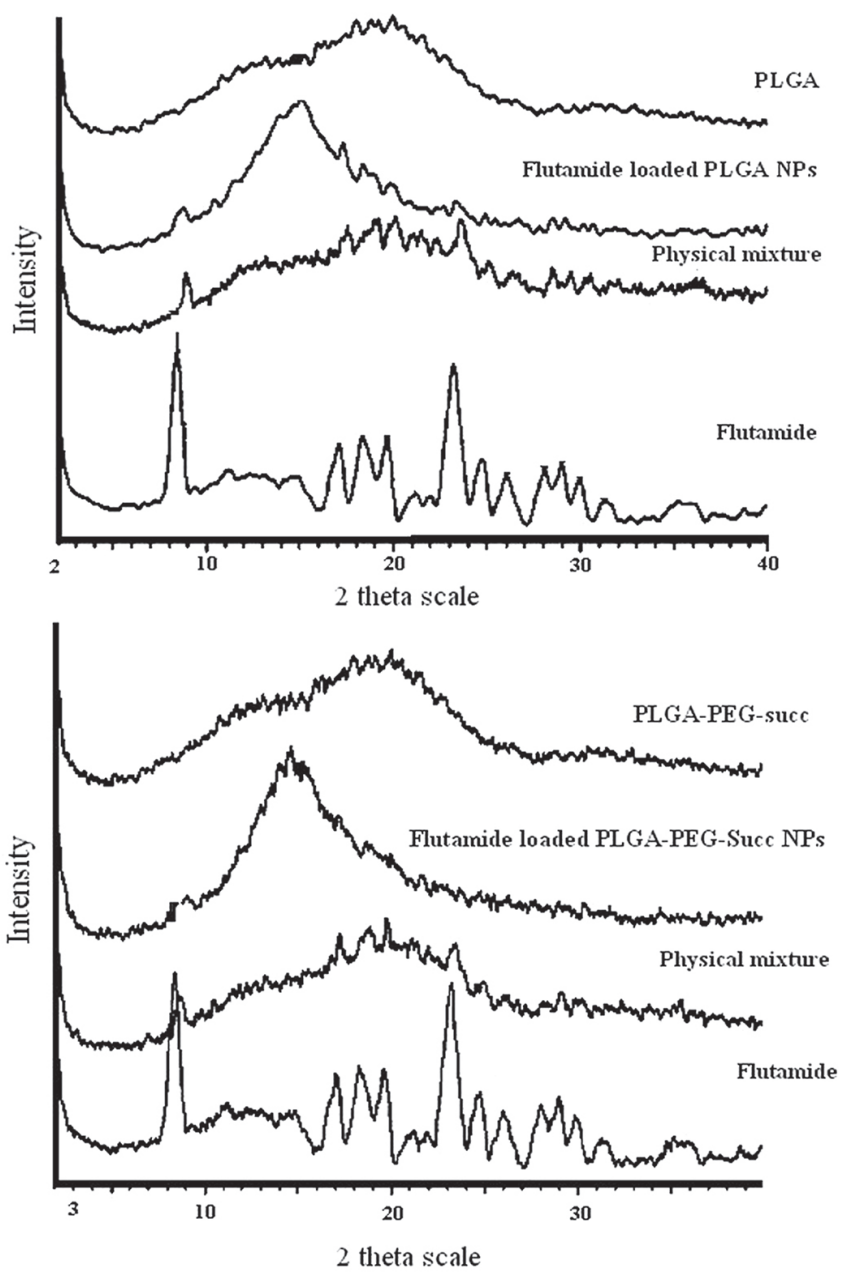

FIGURE 6 - Powder X-ray diffraction of intact flutamide powder, physical mixtures, flutamide-loaded nanoparticles. 
signifying a drug amorphization or its dissolution in the amorphous carrier (Figure 6). XRD results were consistent with the findings obtained from DSC analysis. Concisely, the DSC and XRD studies confirmed a decrease in drug crystallinity in the NPs (Figure 5 and Figure 6)

\section{In vitro release}

FLT release profiles from intact drug powder and the formulated drug-polymer NPs are shown in Figure 7. As can be seen, the intact drug powder had a lower dissolution rate, which could be due to poor wettability and the low aqueous solubility of the drug.

All the NPs demonstrated a steady and uniform drug release profile in comparison with the intact drug, which may be because of the diffusion of the drug localized in the PLGA core of the NPs. There were no distinct differences between PLGA-NPs prepared at different ratios, demonstrating that the release rate was not affected by the increase in PLGA in the NPs.

The release profiles from PLGA-PEG-Praz NPs have more dissolution rate in comparison with other formulations, probably due to the presence of the soluble polymer (PEG) in the matrix body of these NPs, which in turn increases the water penetration and hence dissolution and diffusion. Similar observations were reported by previous studies on bovine serum albuminand cyclosporin-loaded PLGA-PEG NPs (Li et al., 2001; Tang et al., 2012). The release data of nanoparticle formulations were fitted into 11 release mathematical models including zero-order, first-order, square root of mass, three seconds root of mass, Higuchi square root, Hixson-Crowell cube root, Peppas, Peppas-Sahlin, linear probability, Logarithmic probability, and Weibull model. The predicted error values between the observed and calculated release data as well as the coefficient of determination $\left(\mathrm{R}^{2}\right)$ for different formulations were calculated. For the PLGA nanoparticles with a drug to polymer ratios $1: 2$ and 1:3, the Logarithmic probability model was the best-fitted kinetic model with the predicted error range of 5.3\%-6.2\%. The release mechanism might be due to the erosion and degradation of the nanoparticles. For the PLGA nanoparticles with a drug to polymer ratio 1:5 and the PLGA-PEG-Praz nanoparticles with a drug to polymer ratio $1: 3$, the Weibull model was the best-fitted kinetic model with the predicted error range of $4.2 \%$ and $4.3 \%$ (Figure 7 ).

\section{Relative cytotoxic potency}

The viability of PC-3 cells was evaluated after

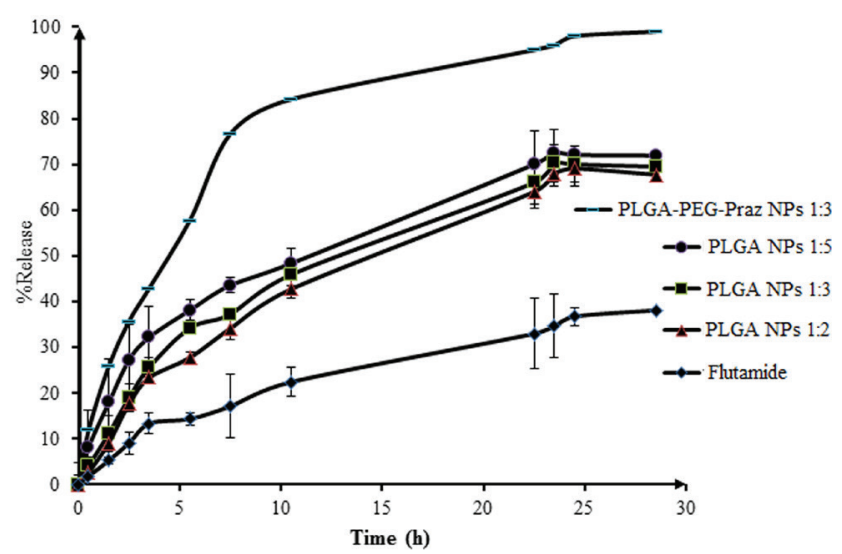

FIGURE 7 - Dissolution profiles of intact flutamide powder and flutamide-loaded nanoparticles with drug to PLGA ratio of 1:2, 1:3, 1:5, and drug to PLGA-PEG-Praz ratio of 1:3.

$48 \mathrm{~h}$ exposure to different concentrations of the FLT and FLT-loaded PLGA-PEG-Praz using MTT method as described in the material and methods. As shown in Figure 8, the FLT was not able to induce cytotoxicity in a PC-3 cell line, up to a concentration of $100 \mu \mathrm{M}$. FLTloaded PLGA-PEG-Praz possessed a good inhibitory effect against PC-3, human cancer prostate cell. Exposure toFLT-loaded PLGA-PEG-Praz for $48 \mathrm{~h}$ resulted in a concentration-dependent decrease in cell viability, with approximate IC 50 of $71.6 \pm 4.3 \mu \mathrm{M}$. It can be concluded that this formulation can increase FLT cytotoxic effect in human prostate cancer cells. However, more details and methods must be employed to explore the molecular mechanism that mediated increase cytotoxic effect of FLT-loaded PLGA-PEG-Praz in PC-3 cell line. Moreover, further studies are underway in our laboratory to evaluate the cytotoxic effect of FLT-loaded PLGAPEG-Praz in other human prostate cancer cells like LNCap and DU-145 (Figure 8).

\section{CONCLUSION}

The present study showed that PLGA-PEG-Praz could be a useful nanocarrier for FLT. PLGA-PEG-Praz was synthesized successfully by a multi-step reaction. Nanoparticles were prepared by quasi-emulsion solvent diffusion technique. As a result, nanoparticles with the efficient loading of FLT were obtained. FLT was in the amorphous form in the nanoparticles. Prazosindecorated nanoparticles had higher loading efficacy and faster release compared to the PLGA nanoparticles. These phenomena altogether make FLT loaded NPs as a potential drug delivery system for treatment of prostate cancer. 


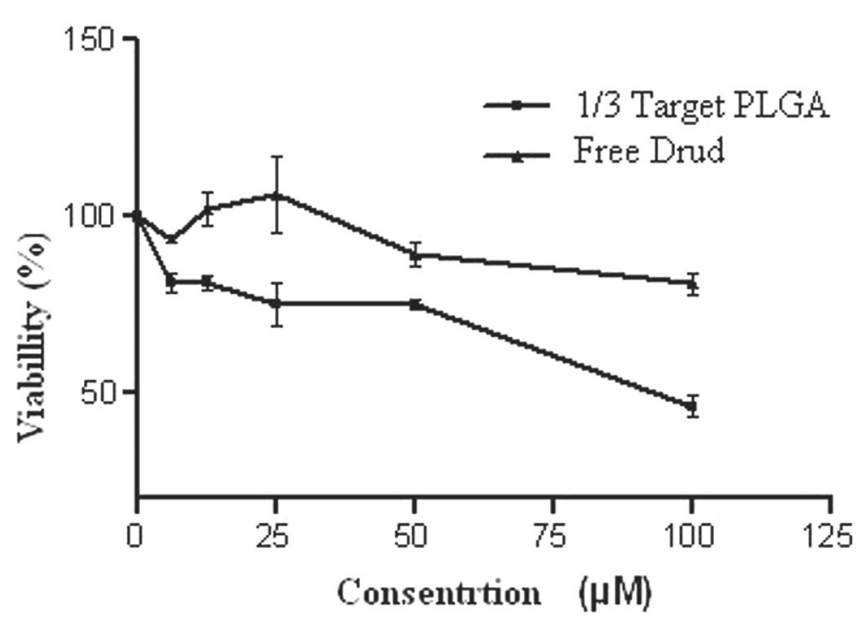

FIGURE 8 - Cell viability of PC-3 cells after treatment with different concentrations ofFL and FLT -loaded PLGA-PEGPraz. Cell viability measured by MTT assay. $\mathrm{IC}_{50}$ value was obtained by plotting thelog 10 of the percentage of proliferation values versus drug concentrations. Data areexpressed as the mean \pm S.E.M of three separate experiments $(n=5)$.

\section{ACKNOWLEDGEMENT}

The authors would like to acknowledge the Research Council of Kermanshah University of Medical Sciences for supporting this work.

\section{CONFLICT OF INTEREST}

The authors declared no conflict of interest.

\section{REFERENCES}

Adlin JN, Gowthamarajan K, Somashekhara C. Formulation and evaluation of nanoparticles containing flutamide. Inter J Chem Tech Res. 2009;1(4):1331-1334.

Alldredge BK, Corelli R, Ernst ME, et al. Applied therapeutics: the clinical use of drugs. Philadelphia: Wolters Kluwer/Lipincot William \& Wilkins; 2013.

Anitha A, Uthaman S, Nair SV, Rangasamy J, Lakshmanan V.-K. Enhanced delivery system of flutamide loaded chitosandextran sulphate nanoparticles for prostate cancer. J Biomed Nanotechnol. 2013;9(3):335-347.

Cun D, Foged C, Yang M, Frøkjaer S, Nielsen HM. Preparation and characterization of poly (DL-lactide-co-glycolide) nanoparticles for siRNA delivery. Int J Pharm. 2010;390(1):7075.
Danhier F, Ansorena E, Silva JM, Coco R, Le Breton A, Préat V. PLGA-based nanoparticles: an overview of biomedical applications. J Control Release. 2012;161(2):505-522.

Ebrahimnejad P, Dinarvand R, Jafari MR, Tabasi SA, Atyabi F. Characterization, blood profile and biodistribution properties of surface modified PLGA nanoparticles of SN-38. Int J Pharm. 2011;406(1):122-127.

Elgindy N, Elkhodairy K, Molokhia A, Elzoghby A. Biopolymeric microparticles combined with lyophilized monophase dispersions for controlled flutamide release. Int $\mathrm{J}$ Pharm. 2011;411(1):113-120.

Farokhzad OC, Langer R. Impact of nanotechnology on drug delivery. ACS nano. 2009;3(1):16-20.

Heidenreich A, Aus G, Bolla M, Joniau S, Matveev VB, Schmid HP, et al. [EAU guidelines on prostate cancer]. Actas Urologicas Espanolas. 2009;33(2):113-126.

Hou S, McCauley LK, Ma PX. Synthesis and erosion properties of PEG-Containing polyanhydrides. Macromol Biosci. 2007;7(5):620-628.

Jokerst JV, Lobovkina T, Zare RN, Gambhir SS. Nanoparticle PEGylation for imaging and therapy. Nanomedicine. 2011;6(4):715-728.

Koopaei MN, Maghazei MS, Mostafavi SH, Jamalifar H, Samadi N, Amini M, et al. Enhanced antibacterial activity of roxithromycin loaded pegylated poly lactide-co-glycolide nanoparticles. DARU J Pharm Sci. 2012;20(1):92.

Lee ES, Na K, Bae YH. Polymeric micelle for tumor $\mathrm{pH}$ and folate-mediated targeting. J Control Release. 2003;91(1):103113.

Li Y-P, Pei Y-Y, Zhang X-Y, Gu Z, Zhou Z, Yuan W, et al. PEGylated PLGA nanoparticles as protein carriers: synthesis, preparation and biodistribution in rats. J Control Release. 2001;71(2):203-211.

Liao CH, Guh JH, Chueh SC, Yu HJ. Anti-angiogenic effects and mechanism of prazosin. The Prostate. 2011;71(9):976-984.

Lin S-C, Chueht S-C, Hsiao C-J, Li TK, Chen TH, Liao CH, et al. Prazosin displays anticancer activity against human prostate cancers: targeting DNA, cell cycle. Neoplasia. 2007;9(10):830839. 
Liu Y, Li K, Pan J, Liu B, Feng SS. Folic acid conjugated nanoparticles of mixed lipid monolayer shell and biodegradable polymer core for targeted delivery of Docetaxel. Biomaterials. 2010;31(2):330-338.

Mahalwar A, Sharma A, Sahu R, Rathore DS. Evaluation of receptor mediated endocytosis on cellular internalization: a comparative study of PEGylated nanoparticles and folate anchored PEGylated nanoparticles on MDA-MB-231 cells. Int J Biol Pharm Res. 2012;3(3):431-443.

Mohammadi G, Nokhodchi A, Barzegar-Jalali M, Lotfipour F, Adibkia K, Ehyaei N, et al. Physicochemical and anti-bacterial performance characterization of clarithromycin nanoparticles as colloidal drug delivery system. Colloids Surf B Biointerfaces. 2011;88(1):39-44.

Mohanraj V, Chen Y. Nanoparticles - A review. Trop J Pharm Res. 2006;5(1):561-573.

Pan J, Feng S-S. Targeted delivery of paclitaxel using folatedecorated poly (lactide)-vitamin E TPGS nanoparticles. Biomaterials. 2008;29(17):2663-2672.

Pan J, Feng S-S. Targeting and imaging cancer cells by folatedecorated, quantum dots (QDs)-loaded nanoparticles of biodegradable polymers. Biomaterials. 2009;30(6):1176-1183.

Samy WM. Class II drugs; a dissolution/bioavailability challenge: Flutamide-loaded spray dried lactose for dissolution control. Int J Drug Dev Res. 2012;4(2):195-204.

Singh R, Lillard JW. Nanoparticle-based targeted drug delivery. Exp Molec Pathol. 2009;86(3):215-223.

Tang L, Azzi J, Kwon M, Mounayar M, Tong R, Yin Q, et al. Immunosuppressive activity of size-controlled PEG-PLGA nanoparticles containing encapsulated cyclosporine A. J Transplant. 2012;2012:896141.
Valizadeh H, Mohammadi G, Ehyaei R, Milani M, Azhdarzadeh M, Zakeri-Milani P, et al. Antibacterial activity of clarithromycin loaded PLGA nanoparticles. Pharmazie. 2012;67(1):63-68.

van Vlerken LE, Vyas TK, Amiji MM. Poly (ethylene glycol)modified nanocarriers for tumor-targeted and intracellular delivery. Pharm Res. 2007;24(8):1405-1414.

Wadajkar AS, Menon JU, Tsai Y-S, Gore C, Dobin T, Gandee L, et al. Prostate cancer-specific thermo-responsive polymer-coated iron oxide nanoparticles. Biomaterials. 2013;34(14):3618-3625.

Xu W, Siddiqui IA, Nihal M, Pilla S, Rosenthal K, Mukhtar $\mathrm{H}$, Gong S. Aptamer-conjugated and doxorubicin-loaded unimolecular micelles for targeted therapy of prostate cancer. Biomaterials. 2013;34(21):5244-5253.

Zhang Z, Lee SH, Feng S-S. Folate-decorated poly (lactideco-glycolide)-vitamin E TPGS nanoparticles for targeted drug delivery. Biomaterials. 2007;28(10):1889-1899.

Zhao A, Zhou Q, Chen T, Weng J, Zhou S. Amphiphilic PEGbased ether-anhydride terpolymers: Synthesis, characterization, and micellization. J Appl Polymer Sci. 2010;118(6):3576-3585.

Zhao H, Yung LYL. Selectivity of folate conjugated polymer micelles against different tumor cells. Int J Pharm. 2008;349(1):256-268.

Zuo Z, Kwon G, Stevenson B, Diakur J, Wiebe LI. Flutamidehydroxypropyl-ß-cyclodextrin Complex: formulation, physical characterization, and absorption studies using the caco-2 in vitro model. J Pharm Pharmaceut Sci. 2000;3(2):220-227.

Received for publication on $02^{\text {nd }}$ May 2017 Accepted for publication on $18^{\text {th }}$ October 2017 